\title{
The Intervention Nurses Start Infants Growing on Healthy Trajectories (INSIGHT) study
}

Ian M Paul ${ }^{1,2^{*}}$, Jennifer S Williams ${ }^{3}$, Stephanie Anzman-Frasca ${ }^{4}$, Jessica S Beiler ${ }^{1}$, Kateryna D Makova ${ }^{5}$, Michele E Marini ${ }^{3}$, Lindsey B Hess ${ }^{3}$, Susan E Rzucidlo ${ }^{6}$, Nicole Verdiglione ${ }^{1}$, Jodi A Mindell ${ }^{7}$ and Leann L Birch ${ }^{8}$

\begin{abstract}
Background: Because early life growth has long-lasting metabolic and behavioral consequences, intervention during this period of developmental plasticity may alter long-term obesity risk. While modifiable factors during infancy have been identified, until recently, preventive interventions had not been tested. The Intervention Nurses Starting Infants Growing on Healthy Trajectories (INSIGHT). Study is a longitudinal, randomized, controlled trial evaluating a responsive parenting intervention designed for the primary prevention of obesity. This "parenting" intervention is being compared with a home safety control among first-born infants and their parents. INSIGHT's central hypothesis is that responsive parenting and specifically responsive feeding promotes self-regulation and shared parent-child responsibility for feeding, reducing subsequent risk for overeating and overweight.

Methods/Design: 316 first-time mothers and their full-term newborns were enrolled from one maternity ward. Two weeks following delivery, dyads were randomly assigned to the "parenting" or "safety" groups. Subsequently, research nurses conduct study visits for both groups consisting of home visits at infant age 3-4, 16, 28, and 40 weeks, followed by annual clinic-based visits at 1,2, and 3 years. Both groups receive intervention components framed around four behavior states: Sleeping, Fussy, Alert and Calm, and Drowsy. The main study outcome is BMI $z$-score at age 3 years; additional outcomes include those related to patterns of infant weight gain, infant sleep hygiene and duration, maternal responsiveness and soothing strategies for infant/toddler distress and fussiness, maternal feeding style and infant dietary content and physical activity. Maternal outcomes related to weight status, diet, mental health, and parenting sense of competence are being collected. Infant temperament will be explored as a moderator of parenting effects, and blood is collected to obtain genetic predictors of weight status. Finally, second-born siblings of INSIGHT participants will be enrolled in an observation-only study to explore parenting differences between siblings, their effect on weight outcomes, and carryover effects of INSIGHT interventions to subsequent siblings.
\end{abstract}

Discussion: With increasing evidence suggesting the importance of early life experiences on long-term health trajectories, the INSIGHT trial has the ability to inform future obesity prevention efforts in clinical settings.

Trial registration: NCT01167270. Registered 21 July 2010.

Keywords: Obesity, Prevention, Infancy, Responsiveness, Home visitation, Feeding, Parenting

\footnotetext{
* Correspondence: ipaul@psu.edu

'Department of Pediatrics, HS83, Penn State College of Medicine, 500

University Dr., 17033 Hershey, PA, USA

${ }^{2}$ Public Health Sciences, Penn State College of Medicine, Hershey, PA, USA

Full list of author information is available at the end of the article
} 


\section{Background}

Overweight and rapid weight gain during infancy are associated with increased later risk of overweight [1-24], as well as numerous co-morbidities including hypertension [25-28], coronary heart disease [29,30], type 2 diabetes mellitus [24,31,32], and asthma [33-35]. Because infancy is a critical period of developmental plasticity with longlasting metabolic and behavioral consequences [36-38], interventions developed for delivery during this period may alter long-term risk for obesity and associated comorbidities. With $22.8 \%$ of $2-5$ year old US children already meeting criteria for overweight [39], and overweight by age 5 years strongly associated with later life overweight [40], early interventions to address this epidemic are needed. However, while modifiable factors promoting overweight and rapid growth during infancy have been identified [41-43], until recently, studies aimed at the primary prevention of obesity through infancybased interventions have not been conducted $[44,45]$.

This paper describes the Intervention Nurses Start Infants Growing on Healthy Trajectories (INSIGHT) study, a prospective, two-arm, randomized, controlled trial evaluating the efficacy of a responsive parenting intervention designed to prevent rapid infant weight gain and childhood obesity among first-born infants. The parenting intervention is being compared with a home safety control, in a birth cohort of infants and their parents. The study will follow families until first-borns are at least 3 years old with body mass index (BMI) as the study's primary outcome. This outcome provides significant insight into long-term obesity risk [40].

INSIGHT's parenting intervention is grounded in the developmental literature on parenting sensitivities $[46,47]$ and centers on responsive feeding, such that parents are taught how to identify and respond sensitively and appropriately to infant hunger and satiety cues. Such early intervention is hypothesized to positively influence the developing controls of food intake by avoiding controlling, restrictive, or coercive feeding by parents that can attenuate children's responsiveness to hunger and satiety cues promoting eating in the absence of hunger, preferences for energy dense foods, and increased obesity risk [48,49]. INSIGHT's central hypothesis is that responsive feeding promotes self-regulation and shared parent-child responsibility for feeding, reducing risk for overeating and overweight [50].

In this study, nurses deliver interventions to first-time parents and their infants in both study groups at four home visits in the first year after birth followed by annual clinical research center visits at age 1,2 , and 3 years. The parenting intervention teaches first-time parents to interact with their infants in a way that is prompt, emotionally supportive, contingent, and developmentally appropriate. Behavioral states (alert and awake, fussy, drowsy, sleeping) serve as a foundation for messages as several portions of the intervention focus on transitioning infants out of the fussy state and into either the alert and awake or the sleeping state with appropriate methods. Behaviors were chosen for our intervention from each of these states that are modifiable, linked to obesity risk, and contain lifestyle benefits for parents that will serve as motivation for behavior change. These additional benefits make the obesity prevention goal "stealth" as described by Robinson [51].

INSIGHT differs from current practice which typically focuses on nutrition sufficiency during the first months after birth. Instead, INSIGHT recognizes that feeding is commonly used as a routine first response to infant and toddler distress and instead promotes parental responsiveness to their child's needs [52-54]. When feeding is responsive to children's needs, shared responsibility in feeding begins to develop. As in other areas of development, this provides opportunities for self-regulation as children assume an increasing role in determining when and how much to consume. For future clinical application, this approach has the advantage of allowing healthcare providers to promote positive parenting behaviors associated with responsive feeding as opposed to the more negative theme of prevention of obesity and its comorbidities.

The framework of responsive parenting underlies the specific lessons in each of the four behavioral states, including instructing parents: a) to recognize infant hunger and satiety cues as well as use feeding more selectively in response only to hunger, b) to use alternatives to feeding to soothe a fussy, but non-hungry infant and toddler, c) to provide children appropriate portions of healthy foods and allow children to determine the amount consumed, d) to improve acceptance of developmentally appropriate foods such as vegetables by using repeated exposure and positive role modeling, e) to develop good sleep hygiene and $f$ ) to actively engage infants in play time in order to reduce sedentary behaviors. In addition to these messages, intervention parents are given education on growth charts, the meaning of growth chart percentiles, and healthy growth patterns during early life.

\section{Obesogenic parenting and the need for parental responsiveness today}

Human biology evolved to promote survival in the context of food scarcity, biasing us to eat opportunistically and lay down fat stores essential for survival in times of scarcity. Within an ecological framework, parents protect their children from these perceived environmental threats to protect their health and development [55], and traditional feeding practices evolved during times when food scarcity and disease were threats to child health. Because loss of appetite is often a symptom of child illness and because adequate food and fluid intake 
is critical to child survival, traditional feeding practices are not contingent on child hunger, and feeding is the "default" response to infant distress [56-58]. Accordingly, traditional feeding practices include strategies intended to soothe infant distress and promote intake, growth, and health such as use of feeding as the first response to crying and other distress, offering preferred foods, promoting intake in the absence of hunger, offering large portions, coercing children to eat beyond satiety, and providing palatable, preferred foods [52-54].

Today in the US and many other countries worldwide, the obesogenic environment promotes an excessively positive energy balance, overweight, and obesity, and too much food has become the major environmental threat to child health, yet traditional feeding practices remain in place. Further, the use of feeding to soothe, especially with infants who are high in negativity and cry frequently, can exacerbate the effects of obesogenic environments, promoting overfeeding and overweight and fostering maladaptive eating behaviors affecting intake and obesity risk throughout the lifespan [54]. These eating behaviors include problems in controlling food intake: increased responsiveness to food cues [59-61], reduced responsiveness to hunger and satiety, disinhibited eating and eating in the absence of hunger, and excessive weight gain and obesity $[49,62]$.

\section{Current clinical care does not promote responsive feeding of infants, shared parent-infant feeding responsibility, and healthy diet content}

Currently, clinicians pay limited attention to obesity prevention during infancy [63]. While infant growth is monitored and most clinicians promote breastfeeding, suggest avoidance of infant cereal in bottles, and advise against early introduction of complementary foods and fruit juice, guidance aimed at early life obesity prevention often stops there. While initially appropriate, the focus for newborns and infants is typically on promoting adequate weight gain rather than preventing excessive weight gain. For example, immediately after birth mothers are typically instructed to wake their infants to feed at least every 3-4 hours for several weeks [64]. While this is necessary initial advice to help newborns regain weight lost shortly after birth, clinicians are far less consistent in instructing parents when to stop this practice and how to identify and rely on infant hunger and satiety cues to guide feeding. Typical anticipatory guidance in pediatric healthcare does not discourage the use of feeding to soothe for non-hunger related infant distress nor does it advise against feeding as a reward for positive behaviors later in infancy and childhood unless obvious overweight or obesity develops.

Current clinical care does focus on timing of introduction of foods - solids at 4 to 6 months, finger foods at 6 months, no cow's milk until 1 year, etc. While guidance about what and when to feed infants is provided, little evidence-based direction is given on how to feed infants to promote subsequent healthy eating habits, including the aforementioned sensitive feeding styles, as well as feeding practices that promote acceptance of healthy foods and flavors in our obesogenic environment. However, interventions during infancy can produce healthier eating behaviors. For example, it is accepted that infants have innate preferences for sweet and salty tastes and are "neophobic", rejecting new foods that are not sweet or salty [65]. Given this set of predispositions, typical infants will readily accept sweet and salty foods such as sweetened drinks and French fries. In contrast, healthy foods such as pureed vegetables, meats, infant cereals, and dairy products, which are not high in sugar or salt, are likely to be initially rejected. Birch and colleagues have conducted research demonstrating that infants typically need several opportunities to sample new foods before intake increases $[66,67]$. The liking for complex flavors that are not dominated by sweet or salty tastes must be learned [65]. Interventions emphasizing repeated opportunities to try healthy, developmentally appropriate foods can have lasting positive effects on acceptance of healthy foods.

Current advice to parents to make healthy food choices for older infants and toddlers is failing to produce the desired outcomes and highlights the significant need for changes to clinical practice. Data from the Feeding Infants and Toddlers Study (FITS) revealed that unhealthy habits start early; energy intakes among infants and toddlers exceeded requirements by $20-30 \%$ [68]. In addition to consuming too much energy, children 4 to 24 months old ate significant amounts of developmentally inappropriate foods, high in energy density and sometimes deficient in key nutrients, and consumed too few of the foods that should form the basis of a healthy weaning diet $[69,70]$. For example, in children aged 7 and 24 months, $18 \%$ and $33 \%$ consumed no servings of vegetables, respectively, during a given 24-hour period. Twenty-three percent of 7-month old and 33\% of 24-month old children did not consume any fruits. By 15 to 18 months, French fries were the most common vegetable consumed. Clearly, parents of infants and toddlers need better direction on what to feed, how much to feed, and how to promote acceptance of a variety of healthy foods during the transition to the modified adult diet. Evidence that these outcomes can be promoted in a real-world setting is critical to transforming how parents view "picky eaters" while promoting acceptance of healthy diets.

\section{Building on evidence from recent trials}

Until recently, studies aimed at primary prevention of obesity through infancy-based interventions had not been conducted $[44,45]$. However, over the past several years several trials have been completed with additional 
studies underway (Table 1). The first to demonstrate an effect on infant weight status was our pilot study, The SLeeping and Intake Methods Taught to Infants and Mothers Early in life study (SLIMTIME) [71]. In this trial, which informed the design of INSIGHT, we selected two promising interventions for obesity prevention based on Birch's research, recruited first-time mothers who intended to breastfeed, and followed their infants delivered at a single center from birth to 1 year. Research nurses delivered interventions in the home using a $2 \times 2$ randomized, experimental design. The first intervention, "Soothe/Sleep," began when infants were 2-3 weeks old. This intervention focused on promoting responsive feeding especially at night via techniques that trained parents to use feeding and other soothing approaches appropriately and selectively to calm a fussy infant [72]. The goal was to help mothers learn to discriminate their infant's hunger from other distress cues, to use appropriate soothing responses for infant distress, and to prolong infant sleep duration. Our hypothesis was that by helping parents respond appropriately and contingently, this would reduce the use of feeding as the traditional "default" response to infant fussing and crying, and that reducing the use of "feeding to soothe" would reduce the risk of overfeeding and overweight. The second intervention, "Introduction of Solids," focused on the transition to solids, providing information on which foods to offer or limit, information about portion sizes, and strategies for promoting liking and acceptance of healthy complementary foods. Specifically, it was based on Birch's research showing the effectiveness of repeated exposure at reducing food neophobia and promoting infants' acceptance of new vegetables [66,67] and toddlers' acceptance of new table foods. 110 participants completed the year-long study.

In comparing "Soothe/Sleep" intervention infants vs. control, results showed that breastfed intervention infants slept significantly longer at night 16 weeks after birth $(p=.04)$. Compared with controls, the intervention also reduced total number of daily feedings $(p=.008)$ and nocturnal feedings $(p=.003)$ for breastfed infants. Consistent with our framework, the results suggest that our intervention helped parents learn to be responsive while calming infants without feeding in the absence of hunger, thus promoting parenting competence. It also appeared to promote development of infant self-regulation by allowing infants opportunities to self-soothe [90,91]. Third, given the consistently demonstrated relationship between short sleep duration and overweight, obesity and higher body fat for children of all ages including infants $[9,20,43,92-98]$, an intervention that effectively lengthens sleep duration during infancy is potentially preventive, and may have both short- and long-term effects, given that infant sleep difficulty predicts later sleep problems $[99,100]$.
The "Introduction of Solids" intervention focused on the timing of and effective approaches for introducing solid foods. The intervention delayed introduction of solids, increased acceptance of vegetables upon introduction, and increased acceptance of healthy, unfamiliar foods (hummus, cottage cheese, or yogurt) at the age 1 year laboratory visit. Based on intervention-blinded coding of videos, only $10 \%$ of intervention infants rejected an unfamiliar food at age 1 year compared with $25 \%$ of those in the control group [71].

In addition to improving secondary outcomes related to sleeping and feeding, participants receiving both study interventions had significantly lower weight-for-length percentiles at 1 year (43rd percentile) than those in other study groups. The findings suggest both interventions, the first affecting early sleep, soothing, and feeding frequency and the second affecting the infants' reactions to the introduction of solid foods, were required to have a significant effect on weight status, and therefore a multi-component intervention was selected for the larger INSIGHT trial.

\section{Methods/Design}

\section{Overall study design, recruitment, and randomization}

INSIGHT is a two-arm randomized, controlled trial that involves nurses delivering interventions to first-time parents and their infants at four home visits in the first year after birth followed by clinical research center visits at ages 1, 2, and 3 years (Figure 1). Following completion of informed consent, research staff collected data from the newborn medical record, and participating mothers completed baseline demographic questionnaires. Because we are interested in the effect of the intervention program on formula fed and breastfed infants, mothers were contacted via telephone 10 to 14 days following childbirth, and randomized to a study group with stratification performed based on mothers' intended feeding mode (breastfeeding or formula) and sex-specific birth weight for gestational age ( $<50$ th percentile or $\geq 50$ th percentile) [101]. This study was approved by the Penn State College of Medicine's Human Subjects Protection Office and registered at www. clinicaltrials.gov (NCT01167270) prior to enrollment of the first participant.

\section{Participants}

All newborns delivered at the Penn State Milton S. Hershey Medical Center in Hershey, Pennsylvania were screened for participation (Figure 2). Eligible mother-infant dyads for this trial included full-term ( $\geq 37$ weeks gestation), singleton newborns delivered to English-speaking, primiparous mothers $\geq 20$ years of age residing within 50 miles of the center. Mother-newborn dyads were excluded if there was a plan for the newborn to be adopted or move from Central Pennsylvania within 3 years, if a prenatal ultrasound demonstrated evidence of intrauterine growth 
Table 1 Completed and other ongoing randomized, controlled trials aiming to prevent obesity through during infancy \begin{tabular}{lllll}
\hline Name/trial registry & Framework & Sample size & Intervention(s)
\end{tabular} number

\section{Completed trials}

Educational intervention to modify bottlefeeding behaviors [73]

First steps for mommy and Me [74]

SLeeping and Intake Methods Taught to Infants and Mothers Early in Life (SLIMTIME) Study [71]

Healthy Beginnings Trial $[75,76]$

NOURISH Trial [77-79]
Experiential Learning Cycle for Adult Learning

Motivational Interviewing

Responsive Parenting

\author{
- Group intervention for Women, \\ Infants, and Children (WIC) \\ participating mothers of $1-2$ \\ month old formula-fed infants \\ - Increase awareness of satiety \\ cues \\ - Limit bottle size to 6 ounces or \\ less in first 4 months \\ - Primary care provider \\ "negotiations" at well child care \\ to endorse behavior change \\ - Health educator calls between \\ visits to discuss maternal \\ healthy lifestyle plus infant \\ obesity preventive guidance \\ - Printed Materials
}

- Monthly group parent training sessions

- $2 \times 2$ design using home nurse visits among mothers intending to breastfeed

- "Soothe/Sleep" - discriminate hunger vs. other distress, educate on soothing strategies, day/night differences

- "Introduction of Solids" - delay introduction, hunger/satiety cues education (2-3 weeks), repeated exposure to vegetables ( 4-6 months)

- Intensive home nurse visitation over first 2 years plus phone support vs. usual care among socially high-risk families

- Key messages: "Breast is best", "No solids for me until 6 months", "I eat a variety of fruit and vegetables every day", "Only water in my cup", "I am part of an active family"

- Two modules of group parent education and peer support sessions held co-led by dietician and psychologist timed around a) introduction of solids and b) emergence of autonomy and independence
- No difference in daily formula intake at 4-5 months

- Intervention group had greater weight gain than control between time of intervention and follow-up at infant age 4-5 months

- Later introduction of solids

- Modestly less TV viewing

- Larger increases in nocturnal sleep duration from baseline to follow-up and improvements in sleep hygeine

- No significant difference in weight-for-length z-score

- "Soothe/Sleep" breastfeeding infants slept more, had fewer noctural and total daytime feeds

- "Introduction of Solids" infants - later intro \& were more likely to accept novel healthy foods at age 1 year

- Infants receiving both interventions had a significantly lower weight-for-length z-score at age 1 year

- At age 2 years, BMI significantly lower for intervention group vs. control

- Intervention group ate more vegetables, less meals with TV, and more physical activity

- Lower BMI-for-age Z-score and less rapid infant weight gain since birth at 13-14 months 
Table 1 Completed and other ongoing randomized, controlled trials aiming to prevent obesity through during infancy (Continued)

MOMS Project $[80,81]$ Anticipatory Guidance

292

The Infant Feeding Activity and Nutrition Trial (INFANT) [82-84]

Trials with Published Methods

Mi Voglio Bene [85]

Anticipatory Guidance

Anticipatory Guidance

Prevention of

Overweight in Infancy

(POI.nz) [86]

Parent support theory; Social cognitive theory
- Community-based existing
- Parents instructed to overcome neophobia and increase healthy food acceptance through teaching on healthy infant growth and requirements, variability of intake within/ between infants, amount/ timing of snacks, hunger/satiety cues

- Parents instructed to help develop infant self-regulation and healthy diet with lessons on managing food refusal/ neophobia/fussing, developmenta need for autonomy and limit testing, modeling healthy food choices

- Primary care anticipatory guidance-based study comparing 3 interventions delivered at well child care by primary care providers plus handouts: Mother focused (maternal eating habits and modeling eating) vs. Infant focused (serving size, introduction of solids, feeding style) vs. usual care maternal-child health nurse-led groups with dietician led intervention (6 - two hour sessions delivered quarterly) vs. control (usual care)

- Developmentally appropriate guidance on parent feeding style, timing of introduction of solids, nutrition, parent modeling, managing food rejection

No difference with contro group for BMl at age 2 years

feeding practices

- Mothers less likely to use food as a reward or turn meals into a game

- No difference in growth parameters between groups at 1 year

- Mothers in mother and infant focused groups gave less juice and gave more fruit and vegetables than those in the usual care group.

\section{- At age 20 months there was no difference in BMl between groups, but intervention group showed a modest reduction in sweet snack intake and a modest reduction in TV viewing \\ - No group differences in fruit/ veggie/water/sweetened beverage intake, physical activity}

\section{Primary Outcome}

- BMl at age 6 years

- Primary care based delivery of 10 preventive actions (promotion of breastfeeding, delayed introduction of solids, control of protein intake in first 2 years, avoidance of sweetened beverages, avoidance of bottle use after 2 years, promoting physical activity, identification of early adiposity rebound, limit TV viewing, encouraging play, controlling portion size

- 4 arm trial comparing usual care with usual care plus either a Food, Activity, and

Breastfeeding intervention or a Sleep intervention or both interventions delivered in well care supplemented by research nurses, lactation consultants and/or sleep specialists 
Table 1 Completed and other ongoing randomized, controlled trials aiming to prevent obesity through during infancy (Continued)

\begin{tabular}{|c|c|c|c|c|}
\hline Healthy Babies [87] & Theory of Planned Behavior & 372 & $\begin{array}{l}\text { - Paraprofessional home visits } \\
\text { providing guidance on } \\
\text { normative growth and } \\
\text { development and skill-building } \\
\text { on maternal feeding and } \\
\text { feeding responsiveness, }\end{array}$ & - Weight-for-length at age 1 year \\
\hline $\begin{array}{l}\text { Preventing Childhood } \\
\text { Obesity through Early } \\
\text { Feeding and Parenting } \\
\text { Guidance [88] }\end{array}$ & $\begin{array}{l}\text { Personalized Anticipatory } \\
\text { Guidance }\end{array}$ & 140 & $\begin{array}{l}\text { - Community health worker } \\
\text { home visits with focus on } \\
\text { preventing obesogenic feeding } \\
\text { behaviors, parental recognition } \\
\text { of cues, play without screen } \\
\text { time, and good sleep hygiene }\end{array}$ & $\begin{array}{l}\text { - Weight-for-length at ages } 1 \text { and } \\
2 \text { years }\end{array}$ \\
\hline Greenlight Study [89] & Social Cognitive Theory & 865 & $\begin{array}{l}\text { - Low literacy materials delivered } \\
\text { during well child visits by } \\
\text { pediatric residents focusing on } \\
\text { satiety cues, sweetened } \\
\text { beverages, introduction of } \\
\text { solids, portion sizes, non- } \\
\text { sedentary activity, and } \\
\text { breastfeeding }\end{array}$ & - BMl at 2 years \\
\hline
\end{tabular}

retardation, if the newborn's birth weight was $<2500$ grams, or if either the mother or newborn had significant health issues that would affect study participation.

\section{Sample size}

The primary outcome for INSIGHT is BMI Z-score at 3 years. A 0.67 difference in BMI $Z$-scores represents the distance between major centile lines displayed on infant growth charts. This difference is clinically meaningful, and upward percentile crossing of this magnitude has been the operational definition frequently used for rapid weight gain [102]. For this reason we have powered the study to detect a 0.67 difference in BMI Z-scores between the safety control and the parenting intervention groups within each of the feeding modes (intent-to-breast feed or formula feed). To detect this difference with $90 \%$ power and a 5\% Type 1 error rate, 276 participants are required. This includes an anticipated 30\% attrition rate. INSIGHT's initial sample size slightly exceeded this 276 with a total of 316 mother-infant dyads enrolled, 291 dyads randomized, and 279 participants completing the 3-4 week study visit where the interventions begin. This cohort of 279 will be considered the study cohort for outcomes and analyses.

\section{Intervention group}

The parenting intervention uses a responsive parenting framework with obesity prevention messages delivered at each visit that correspond to four infant/toddler behavior states: Drowsy, Sleeping, Fussy, and Alert and Calm (Figure 3). Within the Alert and Calm category are two sub-categories, Active, social play and Feeding.

\section{Drowsy and sleep}

Beginning at the first study home visit and at each subsequent visit, age appropriate sleep hygiene to promote longer sleep duration is discussed. Norms for sleep duration at study visit are discussed, as are strategies to prolong sleep duration. Avoidance of feeding to sleep is a consistent theme as is recognition of how to respond to night wakings without feeding when appropriate based upon norms for intervals between feedings and hunger and satiety cues. More specific guidance was given at developmentally appropriate ages such as the use of swaddle blankets, white noise, and "dream feeds" (parent waking baby to feed before parent goes to bed) during early infancy, as well as how to transition from multiple to single daily naps, establishing a consistent

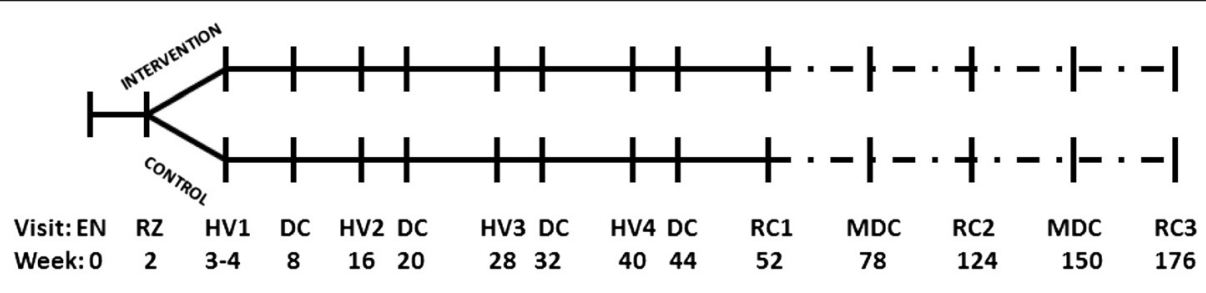

Figure 1 INSIGHT study visit schedule. 


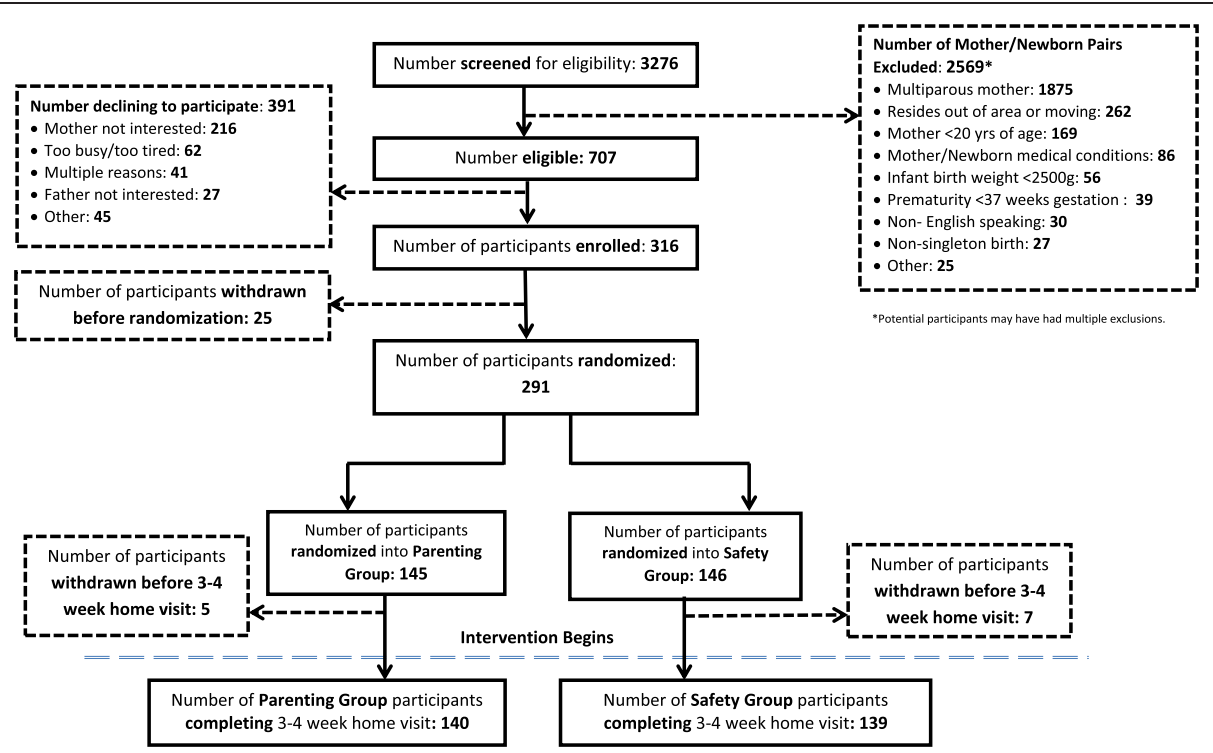

Figure 2 Study CONSORT diagram.

bedtime routine, and when to transition from a crib to a bed for toddlers. Importantly, parents were given individualized feedback based on their infant's sleep hygiene by completing a "Sleep Profile" at 16 and 40 weeks based on the work by Mindell and Sadeh [103]. This feedback allowed parents to both understand how their infant's sleep compares with others at the same age, and also provides tailored strategies to improve sleep duration and reduce nocturnal awakenings.
Fussy

Much of the responsive parenting guidance for the fussy child involves not using food to soothe, but rather emphasizing that food is for hunger, not to soothe fussiness or conversely to reward for good behavior. Additionally, the concept of temperament is introduced to parents to enable them to understand why their baby might be different from others, especially with regards to fussiness. To empower parents with alternative strategies to feeding to

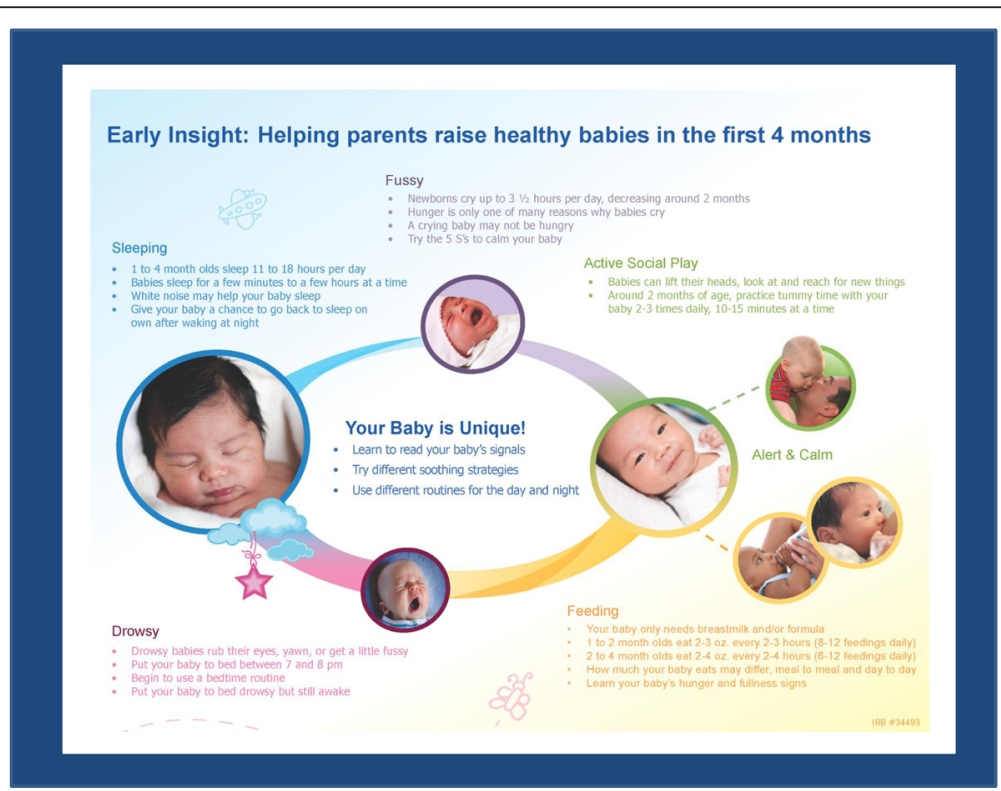

Figure 3 Example of responsive parenting messages delivered for behavioral states. 
calm their infant, the parents are given The Happiest Baby on the Block video [104] in the first weeks following delivery, and the video's calming strategies are demonstrated at the first home visit [105]. Expectations for amounts of daily crying at different points during infancy are also detailed. Later in infancy, expectations for stranger anxiety are discussed, as well as using modeling and emotion coaching to promote healthy emotional development, including the self-regulation of emotions. After age 1 year, strategies are reviewed on how to prevent and handle temper tantrums with The Happiest Toddler on the Block video [106] used for demonstration.

\section{Alert and calm - feeding}

Beginning during early infancy, instructions are given to parents on recognition of infant hunger and satiety cues, appropriate portion sizes, using food for hunger only and not for soothing, reward, or punishment, healthy nutrition for children, and modeling of healthy eating by parents. Initially, this focuses on breast milk or formula with delaying introduction of solids foods, but later guidance discusses how to introduce vegetables, fruits and other solid foods to a developmentally ready child with a focus on overcoming neophobia for those foods that are neither sweet nor salty. As the infant gets older, the concept of shared feeding responsibility is highlighted repeatedly and parents are taught to understand their role in providing healthy choices for their child, and that the child's role is to decide how much to eat based on their hunger and fullness cues. Beverage consumption is a focus throughout the infant and toddler period with concrete recommendations to limit fruit juice consumption to 4 ounces daily with strict avoidance of sugar sweetened beverages as well as how and when to wean a child from a bottle to a cup. The use of portable sippy cups is discussed with a focus on avoidance of frequent drinking of caloric beverages (e.g. milk) at non-meal times. Parents are educated on setting routines and limits around what and when foods are served. At several points, portion sizes for meals as well as snacks are demonstrated via pictures and plastic food replicas, comparing them to an appropriate adult portion pictorially. Picky eating and strategies to overcome this common phenomenon is discussed as the child exerts the typical independence of a toddler.

\section{Alert and calm - active, social play}

Developmentally appropriate physical activity, parental modeling of behavior, and limit setting (e.g. through consistent discipline, avoidance/limiting screen time) are consistent themes in this sub-domain of the INSIGHT intervention. Daily physical activity is encouraged from the beginning of the study through tummy time and parents playing on the floor with their infant each day. When appropriate, outdoor play is specifically encouraged as is parental modeling of exercise. Examples of games and activities where children directly interact with their parents are explicitly described. Avoidance of television, especially during meals, is encouraged with limited screen time after age 2 years allowed though still never during meals.

\section{Growth chart education}

During early infancy, parents are educated on typical patterns of growth and weight gain including factors such as nutrition and genetics that contribute to growth. Beginning at the 16 week home visit, color-coded growth charts are shared with parents similar to those used with older children [107]. These growth charts are used as a foundation for discussions about the definition of percentiles and healthy patterns of growth with tailored feedback based on the individual child's anthropometrics. One specific message communicates that higher percentiles on the growth chart are not desirable in the way that they are for school performance.

\section{Control group}

INSIGHT's control group receives a developmentally appropriate home safety intervention also delivered by visiting nurses. The home safety visits are designed to be equal in length and intensity to the parenting intervention visits and to avoid messages that could impact energy balance. The home safety intervention also is designed within the framework of the four behavioral states. Within the Drowsy and Sleep domains, prevention of Sudden Infant Death Syndrome is initially the focus with carbon monoxide poisoning prevention and bedroom childproofing topics covered later. Within the Fussy category, strategies to prevent Shaken Baby Syndrome and child abuse are discussed initially followed by avoidance of distracted driving, treatment of fever and other first aid remedies, and avoidance of physical force with discipline. Food safety is a repeated theme in the Alert and Calm - Feeding sub-domain beginning with breast milk and formula handling and storage, progressing to baby food handling, food allergens, choking hazards, and safe storage of food sent to childcare. High chair and stove safety issues are also discussed. For the Active, Social Play component, the first topics covered include fire, bath, and car seat safety. Prevention of falls, poison prevention, furniture safety, and toy safety are all covered within the first year. Gun safety and seasonal topics (insect repellant, sunscreen, trick-or-treating, holiday decorations) are then covered with pedestrian safety, booster seat transition, and hand washing.

\section{Measures}

To assess intervention impacts on both the primary outcome and intermediary behavioral processes, INSIGHT 
Table 2 INSIGHT study measures

\begin{tabular}{|c|c|c|c|c|c|c|c|c|c|c|c|c|c|c|c|}
\hline \multirow[t]{2}{*}{ Construct } & \multicolumn{15}{|c|}{ Time points (child age in weeks) } \\
\hline & 0 & 2 & 4 & 8 & 16 & 20 & 28 & 32 & 40 & 44 & 52 & 78 & 104 & 130 & 156 \\
\hline \multicolumn{16}{|l|}{ Anthropometrics and Biological Specimens } \\
\hline Child weight and length/height & $\mathrm{x}$ & & $\mathrm{x}$ & & $\mathrm{x}$ & & $\mathrm{X}$ & & $\mathrm{x}$ & & $\mathrm{X}$ & & $\mathrm{x}$ & & $\mathrm{x}$ \\
\hline Mother weight & $x$ & & & & & & $\mathrm{X}$ & & & & $\mathrm{X}$ & & $\mathrm{x}$ & & $\mathrm{x}$ \\
\hline Mother height, Father weight/height & $\mathrm{x}$ & & & & & & & & & & & & & & \\
\hline Child DNA (blood, cheek swabs) & & & & & & & & & & & $\mathrm{X}$ & & & & \\
\hline Child stool microbiome & & & & & & & & & & & & & $\mathrm{x}$ & & \\
\hline \multicolumn{16}{|l|}{ Child Behavior } \\
\hline Sleep $[108,109]$ & & $\mathrm{x}$ & & & $\mathrm{x}$ & & & & $x$ & & $\mathrm{X}$ & & & $\mathrm{x}$ & $\mathrm{x}$ \\
\hline Dietary intake $[110,111]^{*}$ & & $\mathrm{x}$ & & & $\mathrm{x}$ & & $\mathrm{X}$ & & $x$ & & $\mathrm{X}$ & & $\mathrm{x}$ & & $\mathrm{x}$ \\
\hline Temperament $[112,113]$ & & & & & $\mathrm{x}$ & & & & & & $\mathrm{X}$ & & $\mathrm{x}$ & & \\
\hline Reaction to foods & & & & & $\leftarrow \mathrm{X} \rightarrow$ & & & & & & $\mathrm{X}$ & & & & $\mathrm{x}$ \\
\hline Motor milestones [114] & & & & & & & & $x$ & & & $\mathrm{X}$ & & & & \\
\hline Appetite [115] & & & & & & & & & & $\mathrm{x}$ & & & & & \\
\hline Videotaped self-feeding & & & & & & & & & & & $\mathrm{X}$ & & & & \\
\hline Neophobia [116] & & & & & & & & & & & $\mathrm{X}$ & & & & $\mathrm{x}$ \\
\hline Eating behavior [117] & & & & & & & & & & & & & & $\mathrm{x}$ & \\
\hline \multicolumn{16}{|l|}{ Parenting } \\
\hline Feeding to soothe $[54]^{*}$ & & $\mathrm{x}$ & & $x$ & $x$ & & & $\mathrm{x}$ & & $x$ & & $\mathrm{x}$ & & $x$ & \\
\hline Infant feeding mode [118] & & $\mathrm{x}$ & & $\mathrm{x}$ & & $\mathrm{X}$ & & $\mathrm{x}$ & & & $\mathrm{X}$ & $\mathrm{X}$ & & $x$ & \\
\hline Self-efficacy $[119,120]$ & & $\mathrm{x}$ & & $\mathrm{x}$ & & & & $\mathrm{x}$ & & & $\mathrm{X}$ & & & & $\mathrm{x}$ \\
\hline Feeding practices \& styles $[121,122]$ & & & & & $\mathrm{x}$ & & $\mathrm{X}$ & & & & & & & $\mathrm{x}$ & \\
\hline Structure and Control Feeding & & & & & & & & & & & $\mathrm{X}$ & & $\mathrm{x}$ & & \\
\hline \multicolumn{16}{|c|}{ Maternal Psychosocial Variables and Behavior } \\
\hline Postpartum depression [123] & & & $\mathrm{x}$ & & & & & & $x$ & & & & & & \\
\hline Restrained/disinhibited eating [124] & & & & & $\mathrm{x}$ & & & & & & & & & & \\
\hline Eating habits $[125-127]^{*}$ & & & & & $\mathrm{x}$ & & & $\mathrm{x}$ & & & $\mathrm{X}$ & & & & \\
\hline Sleep $[128]^{*}$ & & & & & $\mathrm{x}$ & & & & & & & & $\mathrm{X}$ & & \\
\hline Dietary intake $[110,111]^{*}$ & & & & & & & & & & $\mathrm{x}$ & & & & $\mathrm{x}$ & \\
\hline Trait anxiety [129] & & & & & & & & & & & & $\mathrm{X}$ & & & $\mathrm{X}$ \\
\hline \multicolumn{16}{|l|}{ Health Literacy [130] } \\
\hline \multicolumn{16}{|l|}{ Family Context } \\
\hline Home environment (observed) & & & $\mathrm{x}$ & & $\mathrm{x}$ & & $\mathrm{X}$ & & $x$ & & & & & & \\
\hline Family functioning $[131,132]^{*}$ & & & & $\mathrm{x}$ & & & $\mathrm{X}$ & & & & & $\mathrm{X}$ & & & \\
\hline Playtime and activity [133]* & & & & $\mathrm{x}$ & & $\mathrm{X}$ & & & & & $\mathrm{X}$ & & $\mathrm{x}$ & & $\mathrm{X}$ \\
\hline TV viewing and family meals & & & & & & $\mathrm{x}$ & & & & $\mathrm{x}$ & & $\mathrm{X}$ & & $\mathrm{x}$ & \\
\hline Yard and recreational space [134]* & & & & & & & & & $\mathrm{x}$ & & & & & & \\
\hline Food insecurity [135] & $\mathrm{x}$ & & & & & & & & & & $\mathrm{X}$ & & $\mathrm{x}$ & & $\mathrm{x}$ \\
\hline \multicolumn{16}{|l|}{ Background, Demographics, and Covariates } \\
\hline Demographics and Health [118]* & $\mathrm{x}$ & & & $\mathrm{x}$ & & $\mathrm{x}$ & & & & & $\mathrm{X}$ & & $\mathrm{x}$ & & $\mathrm{x}$ \\
\hline Development knowledge [136]* & & $x$ & $x$ & & $\mathrm{x}$ & & $\mathrm{x}$ & & $x$ & & & & & & $\mathrm{x}$ \\
\hline
\end{tabular}

*Indicates modified measure - need confirmation that correct ones modified. 
data collection includes measures divided into the following categories: Anthropometrics and Biological Specimens, Infant/Child Behavior, Parenting, Maternal Psychosocial Variables and Behavior, Family Context, and Background/Demographics/Covariates. As detailed in Table 2, many of the measurements are assessed repeatedly.

\section{Second child study}

Beginning with Sir Francis Galton's English Men of Science published in 1874, researchers have examined relationships between birth order and outcomes related to health, achievement, behavior, and intelligence [137-139]. Yet despite observations over the past 140 years regarding birth order, few have prospectively evaluated differences in parenting between successive siblings as a source of the disparities between first- and second-born children. What is established is that while mothers spend more time interacting with their first-born during infancy [140,141], they are more likely to use restrictive or coercive parenting strategies as first described by Lasko in 1954 [142]. Hilton later found that first-time mothers are significantly more interfering, extreme in response, and inconsistent with parenting response than mothers with their later born children [143]. These findings suggest that parents are less likely to use responsive parenting practices with their firstborns than with later-borns.

A recent review of studies examining the effect of birth order on parenting by Kaley et al. [144] reports that evidence is scant and that to date, no studies have prospectively examined differences in parenting of firstand second-born siblings within the same family beginning at birth. However, the review identified several potentially modifiable postnatal factors affecting infant obesity risk: sleep duration, feeding style, and parental regulation of distress.

Capitalizing on the infrastructure and extensive data collection occurring as part of INSIGHT, a second-related project, SIBSIGHT, adds two major pieces by enrolling second born siblings of INSIGHT participants and collecting genetic specimens from both siblings and their parents. Specifically, this translational research is a) prospectively evaluating obesity-related parenting similarities and differences as well as weight-related outcomes between first and second-born siblings, b) exploring how genetic differences among siblings that are associated with appetite, temperament, and obesity susceptibility affect parent-child interactions, degree of responsive parenting, and weight status, and c) determining whether INSIGHT study intervention carryover effects occur among families participating in the observation-only second-born child evaluation.

Data from diverse cultures have shown that first-born children have a higher risk for obesity [145-152] despite the fact that pregnancy related risk factors for childhood obesity (high pre-pregnancy body mass index, high gestational weight gain, occurrence of gestational diabetes, high birth weight) are more common during pregnancies with second-born children. This suggests that postnatal factors related to parenting are the cause of the disparity between first and second born children's obesity risk. Using the conceptual framework of responsive parenting, it can be hypothesized that mothers have improved responsiveness and more appropriate caretaking behaviors due to the experience gained with their first child. This hypothesis will be tested by comparing the $>100$ second-born siblings that can be expected to be born during the funding period with their older siblings with the additional goal to explore how differences in genetic susceptibility to obesity and observed differences in appetite and temperament moderate associations between responsive parenting and weight status at age one year. Data collection for second born children is similar to that demonstrated for the first born in the first year after birth with added aims assessing a) the relationship between infant oral and gut microbiome with weight outcomes and b) the role of epigenetics on obesity development as determined from placenta, cord blood, and peripheral blood obtained at 1 year.

\section{Discussion}

There are few proven prevention strategies available to combat the obesity epidemic. With increasing evidence suggesting the importance of early life experiences on long-term health trajectories, the results of the INSIGHT trial have the ability to inform future obesity prevention efforts in clinical settings. The responsive parenting framework grounded in the developmental literature dovetails nicely into aspects of pediatric care that are already present, but require modifications in the current obesogenic environment.

\section{Competing interests}

The authors declare that they have no competing interests.

\section{Authors' contributions}

IMP and LLB led all aspects of the study concept and design. JSW, SAF, JSB, KDM, MEM, LBH, SER, NV, and JAM all made substantial contributions to portions of the study design. All authors have been involved in the critical revision of the manuscript and have given final approval to the submitted version.

\section{Acknowledgements}

This project is supported by grants R01DK088244 and R01DK099364 from the National Institute of Diabetes and Digestive and Kidney Diseases (NIDDK). Additional support was received from the Children's Miracle Network at Penn State Children's Hospital. The authors acknowledge Jennifer Stokes, RN, Patricia Carper, RN, Amy Shelly, LPN, Gabrielle Murray, RN, Heather Stokes, Karen Powers, Chelsea Rose, BA, Katherine Balantekin, MS, RD, Julia Bleser, MSPH, Erin Berg, RN, and Brittany James, MS for their assistance with this project. 


\section{Author details}

'Department of Pediatrics, HS83, Penn State College of Medicine, 500 University Dr., 17033 Hershey, PA, USA. ${ }^{2}$ Public Health Sciences, Penn State College of Medicine, Hershey, PA, USA. ${ }^{3}$ Center for Childhood Obesity Research, Penn State College of Health and Human Development, University Park, PA, USA. ${ }^{4}$ Friedman School of Nutrition Science and Policy, Tufts University, Boston, MA, USA. ${ }^{5}$ Biology, Eberly College of Sciences, Penn State University, University Park, PA, USA. 'Surgery, Penn State College of Medicine, Hershey, PA, USA. ${ }^{7}$ Psychology, Saint Joseph's University, Philadelphia, PA, USA. ${ }^{8}$ Department of Foods and Nutrition, University of Georgia, Athens, GA, USA

Received: 28 May 2014 Accepted: 9 July 2014 Published: 18 July 2014

\section{References}

1. Fisch RO, Bilek MK, Ulstrom R: Obesity and leanness at birth and their relationship to body habitus in later childhood. Pediatrics 1975, 56(4):521-528

2. Charney E, Goodman HC, McBride M, Lyon B, Pratt R: Childhood antecedents of adult obesity: do chubby infants become obese adults? N Engl J Med 1976, 295(1):6-9.

3. Whitaker RC, Wright JA, Pepe MS, Seidel KD, Dietz WH: Predicting obesity in young adulthood from childhood and parental obesity. $N$ Engl J Med 1997, 337(13):869-873.

4. Guo SS, Wu W, Chumlea WC, Roche AF: Predicting overweight and obesity in adulthood from body mass index values in childhood and adolescence. Am J Clin Nutr 2002, 76(3):653-658.

5. Mei Z, Grummer-Strawn LM, Scanlon KS: Does overweight in infancy persist through the preschool years? An analysis of CDC Pediatric Nutrition Surveillance System data. Soz Praventivmed 2003, 48(3):161-167.

6. Monteiro PO, Victora CG, Barros FC, Monteiro LM: Birth size, early childhood growth, and adolescent obesity in a Brazilian birth cohort. Int J Obes Relat Metab Disord 2003, 27(10):1274-1282.

7. Sayer AA, Syddall HE, Dennison EM, Gilbody HJ, Duggleby SL, Cooper C, Barker DJ, Phillips DI: Birth weight, weight at 1 y of age, and body composition in older men: findings from the Hertfordshire cohort study. Am J Clin Nutr 2004, 80(1):199-203.

8. Freedman DS, Khan LK, Serdula MK, Dietz WH, Srinivasan SR, Berenson GS: The relation of childhood BMI to adult adiposity: the Bogalusa heart study. Pediatrics 2005, 115:22-27.

9. Reilly JJ, Armstrong J, Dorosty AR, Emmett PM, Ness A, Rogers I, Steer C, Sherriff $A$ : Early life risk factors for obesity in childhood: cohort study. BMJ 2005, 330:1358-1360.

10. Nader PR, O'Brien M, Houts R, Bradley R, Belsky J, Crosnoe R, Friedman S, Mei Z, Susman EJ: Identifying risk for obesity in early childhood. Pediatrics 2006, 118(3):e594-e601.

11. Vogels N, Posthumus DL, Mariman EC, Bouwman F, Kester AD, Rump P, Hornstra G, Westerterp-Plantenga MS: Determinants of overweight in a cohort of Dutch children. Am J Clin Nutr 2006, 84(4):717-724.

12. Jouret B, Ahluwalia N, Cristini C, Dupuy M, Negre-Pages L, Grandjean H, Tauber M: Factors associated with overweight in preschool-age children in southwestern France. Am J Clin Nutr 2007, 85(6):1643-1649.

13. Serdula MK, Ivery D, Coates RJ, Freedman DS, Williamson DF, Byers T: Do obese children become obese adults? A review of the literature. Prev Med 1993, 22(2):167-177.

14. Garn SM, LaVelle M: Two-decade follow-up of fatness in early childhood Am J Dis Child 1985, 139(2):181-185

15. Rolland-Cachera MF, Deheeger M, Guilloud-Bataille M, Avons P, Patois E, Sempe M: Tracking the development of adiposity from one month of age to adulthood. Ann Hum Biol 1987, 14(3):219-229.

16. Muramatsu S, Sato $Y$, Miyao M, Muramatsu T, Ito A: A longitudinal study of obesity in Japan: relationship of body habitus between at birth and at age 17. Int J Obes 1990, 14(1):39-45.

17. Eid EE: Follow-up study of physical growth of children who had excessive weight gain in first six months of life. Br Med J 1970, 2(701):74-76.

18. Ong KK, Ahmed ML, Emmett PM, Preece MA, Dunger DB: Association between postnatal catch-up growth and obesity in childhood: prospective cohort study. BMJ 2000, 320(7240):967-971.
19. Stettler N, Zemel BS, Kumanyika S, Stallings VA: Infant weight gain and childhood overweight status in a multicenter, cohort study. Pediatrics 2002, 109(2):194-199.

20. von Kries R, Toschke AM, Wurmser H, Sauerwald T, Koletzko B: Reduced risk for overweight and obesity in 5- and 6-y-old children by duration of sleep-a cross-sectional study. Int J Obes Relat Metab Disord 2002, 26(5):710-716

21. Taveras EM, Rifas-Shiman SL, Belfort MB, Kleinman KP, Oken E, Gillman MW: Weight status in the first 6 months of life and obesity at 3 years of age. Pediatrics 2009, 123(4):1177-1183.

22. Mellbin T, Vuille JC: Physical development at 7 years of age in relation to velocity of weight gain in infancy with special reference to incidence of overweight. Br J Prev Soc Med 1973, 27(4):225-235.

23. Stettler N, Kumanyika SK, Katz SH, Zemel BS, Stallings VA: Rapid weight gain during infancy and obesity in young adulthood in a cohort of African Americans. Am J Clin Nutr 2003, 77(6):1374-1378.

24. Leunissen RW, Kerkhof GF, Stijnen T, Hokken-Koelega A: Timing and tempo of first-year rapid growth in relation to cardiovascular and metabolic risk profile in early adulthood. JAMA 2009, 301(21):2234-2242.

25. Singhal A, Cole TJ, Fewtrell M, Deanfield J, Lucas A: Is slower early growth beneficial for long-term cardiovascular health? Circulation 2004 109(9):1108-1113.

26. Huxley RR, Shiell AW, Law CM: The role of size at birth and postnatal catch-up growth in determining systolic blood pressure: a systematic review of the literature. J Hypertens 2000, 18(7):815-831.

27. Law CM, Shiell AW, Newsome CA, Syddall HE, Shinebourne EA, Fayers PM, Martyn CN, de Swiet M: Fetal, infant, and childhood growth and adult blood pressure: a longitudinal study from birth to 22 years of age. Circulation 2002, 105(9):1088-1092.

28. Parker L, Lamont DW, Unwin N, Pearce MS, Bennett SM, Dickinson HO, White M, Mathers JC, Alberti KG, Craft AW: A lifecourse study of risk for hyperinsulinaemia, dyslipidaemia and obesity (the central metabolic syndrome) at age 49-51 years. Diabet Med 2003, 20(5):406-415.

29. Eriksson JG, Forsen T, Tuomilehto J, Winter PD, Osmond C, Barker DJ: Catch-up growth in childhood and death from coronary heart disease: longitudinal study. BMJ 1999, 318(7181):427-431.

30. Barker DJ, Osmond C, Forsen TJ, Kajantie E, Eriksson JG: Trajectories of growth among children who have coronary events as adults. $N$ Engl Med 2005, 353(17):1802-1809.

31. Forsen T, Eriksson J, Tuomilehto J, Reunanen A, Osmond C, Barker D: The fetal and childhood growth of persons who develop type 2 diabetes. Ann Intern Med 2000, 133(3):176-182.

32. Bhargava SK, Sachdev HS, Fall CH, Osmond C, Lakshmy R, Barker DJ, Biswas SK Ramii S, Prabhakaran D, Reddy KS: Relation of serial changes in childhood body-mass index to impaired glucose tolerance in young adulthood. $N$ Engl J Med 2004, 350(9):865-875

33. Taveras EM, Rifas-Shiman SL, Camargo CA Jr, Gold DR, Litonjua AA, Oken E, Weiss ST, Gillman MW: Higher adiposity in infancy associated with recurrent wheeze in a prospective cohort of children. J Allergy Clin Immuno/ 2008 , 121(5):1161-1166. e1163.

34. Paul IM, Camera L, Zeiger RS, Guilbert TW, Bacharier LB, Taussig LM, Morgan WJ, Covar RA, Krawiec M, Bloomberg GR, Mauger DT: Relationship between infant weight gain and later asthma. Pediatr Allergy Immunol 2010, 21:82-89.

35. Rzehak P, Wijga AH, Keil T, Eller E, Bindslev-Jensen C, Smit HA, Weyler J, Dom S, Sunyer J, Mendez M, Torrent M, Vall O, Bauer CP, Berdel D, Schaaf B, Chen CM, Bergstrom A, Fantini MP, Mommers M, Wahn U, Lau S, Heinrich J: Body mass index trajectory classes and incident asthma in childhood: results from 8 European birth cohorts-a global allergy and asthma European network initiative. J Allergy Clin Immunol 2013, 131(6):1528-1536

36. Gluckman PD, Hanson MA: Developmental and epigenetic pathways to obesity: an evolutionary-developmental perspective. Int J Obes (Lond) 2008, 32(Suppl 7):S62-S71.

37. Gluckman PD, Hanson MA, Cooper C, Thornburg KL: Effect of in utero and early-life conditions on adult health and disease. N Engl J Med 2008, 359(1):61-73.

38. Conti G, Heckman JJ: The developmental approach to child and adult health. Pediatrics 2013, 131(Suppl 2):S133-S141.

39. Ogden CL, Carroll MD, Kit BK, Flegal KM: Prevalence of childhood and adult obesity in the United States, 2011-2012. JAMA 2014, 311(8):806-814 
40. Cunningham SA, Kramer MR, Narayan KM: Incidence of childhood obesity in the United States. N Engl J Med 2014, 370(5):403-411.

41. Paul IM, Bartok CJ, Downs DS, Stifter CA, Ventura AK, Birch LL: Opportunities for the primary prevention of obesity during infancy. Adv Pediatr 2009, 56(1):107-133.

42. Gillman MW, Rifas-Shiman SL, Kleinman K, Oken E, Rich-Edwards JW, Taveras EM: Developmental origins of childhood overweight: potential public health impact. Obesity (Silver Spring) 2008, 16(7):1651-1656.

43. Anderson SE, Whitaker RC: Household routines and obesity in US preschool-aged children. Pediatrics 2010, 125(3):420-428

44. Hesketh KD, Campbell KJ: Interventions to prevent obesity in $0-5$ year olds: an updated systematic review of the literature. Obesity (Silver Spring) 2010, 18(Suppl 1):S27-S35.

45. Ciampa PJ, Kumar D, Barkin SL, Sanders LM, Yin HS, Perrin EM, Rothman RL: Interventions aimed at decreasing obesity in children younger than 2 years: a systematic review. Arch Pediatr Adolesc Med 2010, 164(12):1098-1104.

46. Ainsworth MDS, Blehar MC, Waters E, Wall S: Patterns of Attachment: A Psychological Study of the Strange Situation. Oxford, England: Lawrence Erlbaum; 1978

47. van den Boom DC: The influence of temperament and mothering on attachment and exploration: an experimental manipulation of sensitive responsiveness among lower-class mothers with irritable infants. Child Dev 1994, 65(5):1457-1477.

48. Davison KK, Birch LL: Childhood overweight: a contextual model and recommendations for future research. Obes Rev 2001, 2(3):159-171.

49. Savage JS, Fisher JO, Birch LL: Parental influence on eating behavior: conception to adolescence. J Law Med Ethics 2007, 35(1):22-34.

50. Fisher JO, Birch LL: Feeding children in an environment of plenty: Lessons from the laboratory. In Eating Behaviors of the Young Child: Prenatal and Postnatal Influences on Healthy Eating. Edited by Birch LL, Dietz W. Elk Grove Village: American Academy of Pediatrics; 2007:141-156.

51. Robinson TN: Stealth Interventions for Obesity Prevention and Control: Motivating Behavior Change. In Obesity Prevention: The Role of Brain and Society on Individual Behavior. Edited by Dube L, Behcara A, Dagher A, Drewnoski A, LeBel J, James P, Yada R. London, UK: Elsevier Inc; 2010:319-327.

52. Anzman SL, Rollins BY, Birch LL: Parental influence on children's early eating environments and obesity risk: implications for prevention. Int $J$ Obes (Lond) 2010, 34(7):1116-1124.

53. Birch LL: Child feeding practices and the etiology of obesity. Obesity (Silver Spring) 2006, 14(3):343-344

54. Stifter CA, Anzman-Frasca S, Birch LL, Voegtline K: Parent use of food to soothe infant/toddler distress and child weight status: an exploratory study. Appetite 2011, 57(3):693-699.

55. LeVine RA, Dixon S, LeVine S, Richman A, Leiderman PH, Keefer $\mathrm{CH}_{\text {, }}$ Brazelton TB: Child Care and Culture. Cambridge, England: Cambridge University Press; 1998.

56. LeVine RA, White MI: Human Conditions: The Cultural Basis of Educational Development. New York: Routledge \& Kegan Paul; 1986.

57. Gross RS, Fierman AH, Mendelsohn AL, Chiasson MA, Rosenberg TJ, Scheinmann R, Messito MJ: Maternal perceptions of infant hunger, satiety, and pressuring feeding styles in an urban Latina WIC population. Acad Pediatr 2010, 10(1):29-35.

58. Black MM, Siegel EH, Abel Y, Bentley ME: Home and videotape intervention delays early complementary feeding among adolescent mothers. Pediatrics 2001, 107(5):E67.

59. Birch $L L$, McPhee $L$, Shoba BC, Pirok E, Steinberg $L$ : What kind of exposure reduces children's food neophobia? Looking vs. tasting. Appetite 1987 9(3):171-178.

60. Sullivan S, Birch LL: Pass the sugar; pass the salt: experience dictates preference. Dev Psychol 1990, 26:546-551.

61. Fisher JO, Birch LL: Restricting access to palatable foods affects children's behavioral response, food selection, and intake. Am J Clin Nutr 1999, 69(6):1264-1272

62. Birch LL, Fisher JO, Davison KK: Learning to overeat: maternal use of restrictive feeding practices promotes girls' eating in the absence of hunger. Am J Clin Nutr 2003, 78(2):215-220.

63. McCormick DP, Sarpong K, Jordan L, Ray LA, Jain S: Infant obesity: are we ready to make this diagnosis? J Pediatr 2010, 157(1):15-19.

64. Shelov SP, Hannemann RE (Eds): Caring for Your Baby and Young Child: Birth to Age 5. 5th edition. New York: Bantam Books; 2009:94.
65. Birch LL: Development of food preferences. Annu Rev Nutr 1999, 19:41-62.

66. Sullivan SA, Birch LL: Infant dietary experience and acceptance of solid foods. Pediatrics 1994, 93(2):271-277.

67. Birch LL, Gunder L, Grimm-Thomas K, Laing DG: Infants' consumption of a new food enhances acceptance of similar foods. Appetite 1998, 30(3):283-295

68. Devaney B, Ziegler P, Pac S, Karwe V, Barr SI: Nutrient intakes of infants and toddlers. J Am Diet Assoc 2004, 104(1 Suppl 1):s14-s21.

69. Fox MK, Pac S, Devaney B, Jankowski L: Feeding infants and toddlers study: what foods are infants and toddlers eating? J Am Diet Assoc 2004 104(1 Suppl 1):s22-s30

70. Picciano MF, Smiciklas-Wright H, Birch LL, Mitchell DC, Murray-Kolb L, McConahy KL: Nutritional guidance is needed during dietary transition in early childhood. Pediatrics 2000, 106(1 Pt 1):109-114.

71. Paul IM, Savage JS, Anzman SL, Beiler JS, Marini ME, Stokes JL, Birch LL: Preventing obesity during infancy: a pilot study. Obesity (Silver Spring) 2011, 19(2):353-361.

72. Pinilla T, Birch LL: Help me make it through the night: behavioral entrainment of breast-fed infants' sleep patterns. Pediatrics 1993, 91(2):436-444

73. Kavanagh KF, Cohen RJ, Heinig MJ, Dewey KG: Educational intervention to modify bottle-feeding behaviors among formula-feeding mothers in the WIC program: impact on infant formula intake and weight gain. $J$ Nutr Educ Behav 2008, 40(4):244-250.

74. Taveras EM, Blackburn K, Gillman MW, Haines J, McDonald J, Price S, Oken E. First steps for mommy and me: a pilot intervention to improve nutrition and physical activity behaviors of postpartum mothers and their infants. Matern Child Health J 2010, 15(8):1217-1227.

75. Wen LM, Baur LA, Rissel C, Wardle K, Alperstein G, Simpson JM: Early intervention of multiple home visits to prevent childhood obesity in a disadvantaged population: a home-based randomised controlled trial (Healthy Beginnings Trial). BMC Public Health 2007, 7:76.

76. Wen LM, Baur LA, Simpson JM, Rissel C, Wardle K, Flood VM: Effectiveness of home based early intervention on children's BMI at age 2: randomised controlled trial. BMJ 2012, 344:e3732

77. Daniels LA, Magarey A, Battistutta D, Nicholson JM, Farrell A, Davidson G, Cleghorn G: The NOURISH randomised control trial: positive feeding practices and food preferences in early childhood - a primary prevention program for childhood obesity. BMC Public Health 2009, 9:387.

78. Daniels LA, Mallan KM, Battistutta D, Nicholson JM, Perry R, Magarey A: Evaluation of an intervention to promote protective infant feeding practices to prevent childhood obesity: outcomes of the NOURISH RCT at 14 months of age and 6 months post the first of two intervention modules. Int J Obes (Lond) 2012, 36(10):1292-1298.

79. Daniels LA, Mallan KM, Nicholson JM, Battistutta D, Magarey A: Outcomes of an early feeding practices intervention to prevent childhood obesity. Pediatrics 2013, 132(1):e109-e118.

80. Groner JA, Skybo T, Murray-Johnson L, Schwirian P, Eneli I, Sternstein A Klein E, French G: Anticipatory guidance for prevention of childhood obesity: design of the MOMS project. Clin Pediatr (Phila) 2009, 48(5):483-492.

81. French GM, Nicholson L, Skybo T, Klein EG, Schwirian PM, Murray-Johnson L, Sternstein A, Eneli I, Boettner B, Groner JA: An evaluation of mothercentered anticipatory guidance to reduce obesogenic infant feeding behaviors. Pediatrics 2012, 130(3):e507-e517

82. Campbell K, Hesketh K, Crawford D, Salmon J, Ball K, McCallum Z: The Infant Feeding Activity and Nutrition Trial (INFANT) an early intervention to prevent childhood obesity: cluster-randomised controlled trial. BMC Public Health 2008, 8:103.

83. Hesketh KD, Campbell K, Salmon J, McNaughton SA, McCallum Z, Cameron A Ball K, Gold L, Andrianopoulos N, Crawford D: The Melbourne Infant Feeding, Activity and Nutrition Trial (InFANT) program follow-up. Contemp Clin Trials 2013, 34(1):145-151.

84. Campbell KJ, Lioret S, McNaughton SA, Crawford DA, Salmon J, Ball K, McCallum Z, Gerner BE, Spence AC, Cameron AJ, Hnatiuk JA, Ukoumunne OC, Gold L, Abbott G, Hesketh KD: A parent-focused intervention to reduce infant obesity risk behaviors: a randomized trial. Pediatrics 2013, 131 (4):652-660.

85. Brambilla P, Bedogni G, Buongiovanni C, Brusoni G, Di Mauro G, Di Pietro M, Giussani M, Gnecchi M, lughetti L, Manzoni P, Sticco M, Bernasconi S: "Mi voglio bene": a pediatrician-based randomized controlled trial for 
the prevention of obesity in Italian preschool children. Ital J Pediatr 2010, 36:55.

86. Taylor BJ, Heath AL, Galland BC, Gray AR, Lawrence JA, Sayers RM, Dale K, Coppell KJ, Taylor RW: Prevention of Overweight in Infancy (POI.nz) study: a randomised controlled trial of sleep, food and activity interventions for preventing overweight from birth. BMC Public Health 2011, 11:942.

87. Horodynski MA, Olson B, Baker S, Brophy-Herb H, Auld G, Van Egeren L, Lindau J, Singleterry L: Healthy babies through infant-centered feeding protocol: an intervention targeting early childhood obesity in vulnerable populations. BMC Public Health 2011, 11:868.

88. Reifsnider E, McCormick DP, Cullen KW, Szalacha L, Moramarco MW, Diaz A, Reyna $L$ : A randomized controlled trial to prevent childhood obesity through early childhood feeding and parenting guidance: rationale and design of study. BMC Public Health 2013, 13:880

89. Sanders LM, Perrin EM, Yin HS, Bronough A, Rothman RL: "Greenlight study": a controlled trial of low-literacy, early childhood obesity prevention. Pediatrics 2014, 133:e1724-e1737.

90. Anzman-Frasca S, Liu S, Gates KM, Paul IM, Rovine MJ, Birch LL: Infants' transitions out of a fussing/crying state are modifiable and are related to weight status. Infancy 2013, 18(5):662-686.

91. Anzman-Frasca S, Stifter CA, Paul IM, Birch LL: Negative temperament as a moderator of intervention effects in infancy: testing a differential susceptibility model. Prev Sci 2013. Epub ahead of print: doi:10.1007/ s11121-013-0408-4

92. Locard E, Mamelle N, Billette A, Miginiac M, Munoz F, Rey S: Risk factors of obesity in a five year old population: parental versus environmental factors. Int J Obes Relat Metab Disord 1992, 16(10):721-729.

93. Sekine M, Yamagami T, Hamanishi S, Handa K, Saito T, Nanri S, Kawaminami K, Tokui N, Yoshida K, Kagamimori S: Parental obesity, lifestyle factors and obesity in preschool children: results of the Toyama birth cohort study. J Epidemiol 2002, 12(1):33-39.

94. Agras WS, Hammer LD, McNicholas F, Kraemer HC: Risk factors for childhood overweight: a prospective study from birth to 9.5 years. J Pediatr 2004, 145(1):20-25.

95. Lederman SA, Akabas SR, Moore BJ, Bentley ME, Devaney B, Gillman MW Kramer MS, Mennella JA, Ness A, Wardle J: Summary of the presentations at the conference on preventing childhood obesity, December 8, 2003. Pediatrics 2004, 114:1146-1173.

96. Tian Z, Ye T, Zhang X, Liu E, Wang W, Wang P, Liu G, Yang X, Hu G, Yu Z: Sleep duration and hyperglycemia among obese and nonobese children aged 3 to 6 years. Arch Pediatr Adolesc Med 2010, 164(1):46-52.

97. Jiang F, Zhu S, Yan C, Jin X, Bandla H, Shen X: Sleep and obesity in preschool children. J Pediatr 2009, 154(6):814-818.

98. Taveras EM, Rifas-Shiman SL, Oken E, Gunderson EP, Gillman MW: Short sleep duration in infancy and risk of childhood overweight. Arch Pediatr Adolesc Med 2008, 162(4):305-311.

99. Bernal JF: Night waking in infants during the first 14 months. Dev Med Child Neurol 1973, 15(6):760-769.

100. Touchette E, Petit D, Paquet J, Boivin M, Japel C, Tremblay RE, Montplaisir JY: Factors associated with fragmented sleep at night across early childhood. Arch Pediatr Adolesc Med 2005, 159(3):242-249.

101. Oken E, Kleinman KP, Rich-Edwards J, Gillman MW: A nearly continuous measure of birth weight for gestational age using a United States national reference. BMC Pediatr 2003, 3:6.

102. Ong KK, Loos RJ: Rapid infancy weight gain and subsequent obesity: systematic reviews and hopeful suggestions. Acta Paediatr 2006 95(8):904-908

103. Mindell JA, Du Mond CE, Sadeh A, Telofski LS, Kulkarni N, Gunn E: Efficacy of an internet-based intervention for infant and toddler sleep disturbances. Sleep 2011, 34(4):451-458

104. Karp H, Montee N: The Happiest Baby on the Block: The New Way to Calm Crying and Help Your Baby Sleep Longer; 2006. 128 minutes.

105. Karp H: The Happiest Baby on the Block. New York, NY: Bantam Books; 2002

106. Karp H, Montee N: The Happiest Toddler on the Block. 2004. 69 minutes.

107. Perrin EM, Jacobson Vann JC, Benjamin JT, Skinner AC, Wegner S, Ammerman AS: Use of a pediatrician toolkit to address parental perception of children's weight status, nutrition, and activity behaviors. Acad Pediatr 2010, 10(4):274-281.

108. Sadeh A: A brief screening questionnaire for infant sleep problems: validation and findings for an Internet sample. Pediatrics 2004, 113(6):e570-e577.
109. Henderson JA, Jordan SS: Development and preliminary evaluation of the bedtime routines questionnaire. J Psychopathol Behav Assess 2010, 32(2):271-280

110. Willett WC, Sampson L, Stampfer MJ, Rosner B, Bain C, Witschi J, Hennekens $\mathrm{CH}$, Speizer FE: Reproducibility and validity of a semiquantitative food frequency questionnaire. Am J Epidemio/ 1985, 122(1):51-65.

111. Rockett HR, Wolf AM, Colditz GA: Development and reproducibility of a food frequency questionnaire to assess diets of older children and adolescents. J Am Diet Assoc 1995, 95(3):336-340.

112. Gartstein MA, Rothbart MK: Studying infant temperament via the revised infant behavior questionnaire. Infant Behav Dev 2003, 26:64-86.

113. Putnam SP, Gartstein MA, Rothbart MK: Measurement of fine-grained aspects of toddler temperament: the early childhood behavior questionnaire. Infant Behav Dev 2006, 29(3):386-401.

114. Benjamin Neelon SE, Oken E, Taveras EM, Rifas-Shiman SL, Gillman MW: Age of achievement of gross motor milestones in infancy and adiposity at age 3 years. Matern Child Health J 2012, 16(5):1015-1020.

115. Llewellyn $\mathrm{CH}$, van Jaarsveld $\mathrm{CH}$, Johnson L, Carnell S, Wardle J: Development and factor structure of the baby eating behaviour questionnaire in the gemini birth cohort. Appetite 2011, 57(2):388-396.

116. Pliner P: Development of measures of food neophobia in children. Appetite 1994, 23(2):147-163.

117. Wardle J, Guthrie CA, Sanderson S, Rapoport L: Development of the children's eating behaviour questionnaire. J Child Psychol Psychiatry 2001 42(7):963-970.

118. Fein SB, Labiner-Wolfe J, Shealy KR, Li R, Chen J, Grummer-Strawn LM: Infant feeding practices study II: study methods. Pediatrics 2008, 122(Suppl 2):S28-S35.

119. Crncec R, Barnett B, Matthey S: Development of an instrument to assess perceived self-efficacy in the parents of infants. Res Nurs Health 2008, 31(5):442-453

120. Johnston C, Mash EJ: A measure of parenting satisfaction and efficacy. J Clin Child Psychol 1989, 18:167-175.

121. Thompson AL, Mendez MA, Borja JB, Adair LS, Zimmer CR, Bentley ME: Development and validation of the infant feeding style questionnaire. Appetite 2009, 53(2):210-221.

122. Hughes SO, Power TG, Orlet Fisher J, Mueller S, Nicklas TA: Revisiting a neglected construct: parenting styles in a child-feeding context. Appetite 2005, 44(1):83-92.

123. Cox JL, Chapman G, Murray D, Jones P: Validation of the Edinburgh Postnatal Depression Scale (EPDS) in non-postnatal women. J Affect Disord 1996, 39(3):185-189.

124. Stunkard AJ, Messick S: The three-factor eating questionnaire to measure dietary restraint, disinhibition and hunger. J Psychosom Res 1985, 29(1):71-83.

125. Bauer KW, Hearst MO, Escoto K, Berge JM, Neumark-Sztainer D: Parental employment and work-family stress: associations with family food environments. Soc Sci Med 2012, 75(3):496-504.

126. Berge JM, MacLehose RF, Loth KA, Eisenberg ME, Fulkerson JA, NeumarkSztainer D: Family meals: associations with weight and eating behaviors among mothers and fathers. Appetite 2012, 58(3):1128-1135.

127. National Cancer Institute: Dietary Screener Questionnaire. [http://riskfactor. cancer.gov/studies/nhanes/dietscreen/questionnaires.html]

128. Buysse DJ, Yu L, Moul DE, Germain A, Stover A, Dodds NE, Johnston KL, Shablesky-Cade MA, Pilkonis PA: Development and validation of patientreported outcome measures for sleep disturbance and sleep-related impairments. Sleep 2010, 33(6):781-792.

129. Speilberger CD: Manual for the State-Trait Anxiety Inventory. Palo Alto, CA Consulting Psychologists Press; 1983.

130. Weiss BD, Mays MZ, Martz W, Castro KM, DeWalt DA, Pignone MP, Mockbee J, Hale FA: Quick assessment of literacy in primary care: the newest vital sign. Ann Fam Med 2005, 3(6):514-522.

131. Epstein NB, Baldwin LM, Bishop DS: The McMaster family assessment device. J Marital Fam Ther 1983, 9(2):171-180.

132. Cowan CP, Cowan PA: Who Does What? In Handbook of Family Measurement Techniques. Edited by Touliatos J, Perlmutter B, Straus M. Newbury Park, CA: Sage; 1990.

133. Pate RR: Physical activity assessment in children and adolescents. Crit Rev Food Sci Nutr 1993, 33(4-5):321-326.

134. Bryant MJ, Ward DS, Hales D, Vaughn A, Tabak RG, Stevens J: Reliability and validity of the healthy home survey: a tool to measure factors within 
homes hypothesized to relate to overweight in children. Int J Behav Nutr Phys Act 2008, 5:23.

135. Hager ER, Quigg AM, Black MM, Coleman SM, Heeren T, Rose-Jacobs R, Cook JT, de Cuba SA, Casey PH, Chilton M, Cutts DB, Meyers AF, Frank DA: Development and validity of a 2-item screen to identify families at risk for food insecurity. Pediatrics 2010, 126(1):e26-e32

136. MacPhee D: Knowledge of Infant Development Inventory. Princeton, NJ: Educational Testing Services; 1981.

137. Galton F: English Men of Science: Their Nature and Nurture. London: Macmillan \& Co.; 1874 .

138. Greenwood M Jr, Yule GU: On the determination of size of family and of the distribution of characters in order of birth from samples taken through members of the sibships. J R Stat Soc 1914, 77:179-199.

139. Gini C: Superiority of the eldest. J Hered 1915, 37:37-39.

140. Jacobs BS, Moss HA: Birth order and sex of sibling as determinants of mother-infant interaction. Child Dev 1976, 47(2):315-322.

141. Kilbride HW, Johnson DL, Streissguth AP: Social class, birth order, and newborn experience. Child Dev 1977, 48(4):1686-1688.

142. Lasko JK: Parent behavior toward first and second children. Genet Psychol Monogr 1954, 49(1):98-137.

143. Hilton I: Differences in the behavior of mothers toward first- and later-born children. J Pers Soc Psychol 1967, 7(3):282-290.

144. Kaley F, Reid V, Flynn E: Investigating the biographic, social and temperamental correlates of young infants' sleeping, crying and feeding routines. Infant Behav Dev 2012, 35(3):596-605.

145. Lowe CR, Gibson JR: Weight at third birthday related to birth weight, duration of gestation, and birth order. Br J Prev Soc Med 1953, 7(2):78-82.

146. Jacoby A, Altman DG, Cook J, Holland WW, Elliott A: Influence of some social and environmental factors on the nutrient intake and nutritional status of schoolchildren. Br J Prev Soc Med 1975, 29(2):116-120.

147. Ravelli GP, Belmont L: Obesity in nineteen-year-old men: family size and birth order associations. Am J Epidemiol 1979, 109(1):66-70.

148. Wang $H$, Sekine $M$, Chen $X$, Kanayama $H$, Yamagami T, Kagamimori S: Sib-size, birth order and risk of overweight in junior high school students in Japan: results of the Toyama birth cohort study. Prev Med 2007, 44(1):45-51.

149. Stettler N, Tershakovec AM, Zemel BS, Leonard MB, Boston RC, Katz SH, Stallings VA: Early risk factors for increased adiposity: a cohort study of African American subjects followed from birth to young adulthood. Am 」 Clin Nutr 2000, 72(2):378-383.

150. Celi F, Bini V, De Giorgi G, Molinari D, Faraoni F, Di Stefano G, Bacosi ML, Berioli MG, Contessa G, Falorni A: Epidemiology of overweight and obesity among school children and adolescents in three provinces of central Italy, 1993-2001: study of potential influencing variables. Eur I Clin Nutr 2003, 57(9):1045-1051.

151. Karaolis-Danckert N, Buyken AE, Kulig M, Kroke A, Forster J, Kamin W, Schuster A, Hornberg C, Keil T, Bergmann RL, Wahn U, Lau S: How pre- and postnatal risk factors modify the effect of rapid weight gain in infancy and early childhood on subsequent fat mass development: results from the multicenter allergy study 90. Am J Clin Nutr 2008, 87(5):1356-1364.

152. Hunsberger M, Formisano A, Reisch LA, Bammann K, Moreno L, De Henauw S, Molnar D, Tornaritis M, Veidebaum T, Siani A, Lissner L: Overweight singletons compared to children with siblings: the IDEFICS study. Nutri Diabetes 2012, 2:e35. doi: 10.1038/nutd.2012.1038

\section{Submit your next manuscript to BioMed Central and take full advantage of:}

- Convenient online submission

- Thorough peer review

- No space constraints or color figure charges

- Immediate publication on acceptance

- Inclusion in PubMed, CAS, Scopus and Google Scholar

- Research which is freely available for redistribution 